Rev. Hist., N²6, vol. 1, Enero-junio 2019: 59 - 82

ISSN 0717-8832

\title{
La concepción nacista de la sociedad: posición doctrinaria en torno al sujeto de cambio y las organizaciones de trabajadores
}

The nacist conception of the society: doctrinal position on the subject of change and the organizations of workers

\author{
Diego Venegas Caro*
}

\section{RESUMEN}

Sectores disconformes provenientes del ibañismo, voces críticas de los partidos Liberal y Conservador (a quienes sindicaban como responsables de la crisis social y moral del Chile post-crack del 29'), en conjunto con individuos que no se sintieron interpretados en el espectro político influidos por el auge nacionalista a nivel mundial, dieron vida al Movimiento Nacional-Socialista de Chile en 1932.

Mediante una visión política que buscó diferenciarse del hitlerismo y el fascismo italiano, autodenominada como "nacismo", propusieron una concepción crítica de la sociedad, y una vía política de superación de la crisis, teniendo como base un nacionalismo antiliberal y antimarxista. Es así que en este artículo se estudiará tanto el sujeto de cambio, como el rol de las organizaciones de trabajadores, contenidas en la concepción nacista de la sociedad.

Palabras claves: Fascismo chileno, Movimiento Nacional-Socialista, Nacismo, Tercerposicionismo.

\section{ABSTRACT}

Non-conforming sectors from the "ibañismo", critical voices of the Liberal and Conservative parties (accused as responsible for the social and moral crisis of the post crack of 29' period), togheter with individuals who did not feel they were interpreted in the political spectrum influenced due to the nationalist boom worldwide, formed the National-Socialist Movement of Chile in 1932.

Through a political vision that sought to differentiate itself from Hitlerism and Italian fascism, selfdenominated as "Nacism", they proposed a critical conception of society, and a political way to overcome the crisis, based on an antiliberal and anti-Marxist nationalism. This article focused on both the subject of change and the role of workers' organizations contained in the nacist conception of society.

Keywords: Chilean Fascism, National-Socialist Movement, Nacism, Thirdpositionism.

Recibido: noviembre 2018

Aceptado: mayo 2019

\footnotetext{
* Magister en Historia, Universidad del Biobío. E-mail: devenegas1402@gmail.com
} 


\section{Introducción}

El Movimiento Nacional Socialista chileno se sitúa dentro de un contexto político nacional e internacional de creciente tensión social, de cuestionamiento al sistema democrático liberal, y de la puesta en tela de juicio la validez del capitalismo. Esta colectividad se enmarcó dentro de las agrupaciones fascistas que, si bien es cierto eran antimarxistas, criticaban abiertamente muchos postulados que defendía la derecha liberal.

Esta agrupación estuvo marcada por la marginalidad ${ }^{1}$, no teniendo gran éxito electoral y de masas en Chile ${ }^{2}$, debiendo fusionarse con otras agrupaciones políticas de similares posiciones doctrinarias, o con una plataforma común de acción, como fue el Partido Agrario Laborista ${ }^{3}$. Expresiones políticas ultraconservadoras de corte nacionalista, como el nacismo, neonazismo y fascismo han sido reducidas a las sombras de las corrientes políticas chilenas, no pudiendo encajar con plenitud en el sistema de partidos, gozando de efímera existencia. Sin perjuicio de lo anterior, han rivalizado con las derechas ${ }^{4}$, disputando similares - si es que no idénticossectores sociales y electorales.

Desde el punto de vista historiográfico, en vista al número de producción intelectual referida a esta organización, hemos podido colegir que ha habido escaso interés, razón suficiente que nos ha motivado a contribuir para llenar ese vacío. En este punto, tanto la historia política como la "nueva historia política" han sido las perspectivas historiográficas desde donde ha sido analizado el "nacismo con c", enfocándose principalmente en el despliegue histórico de la colectividad.

\footnotetext{
1 Cfr. Klein, Marcus. 2008. La matanza del Seguro Obrero (5 de septiembre de 1938), Santiago de Chile, Globo. Nosotros entenderemos por marginalidad la posición carente de influencia que tiene una colectividad política, en el sistema de partidos chileno, basado en las bajísimas estadísticas electorales, y concretamente, el número de votos alcanzados por esta colectividad. A su vez, no entenderemos por marginalidad, la posición que tenga una colectividad política fuera del sistema de partidos.

2 Consideraremos como éxito la posibilidad de alcanzar el gobierno, o al menos tener una posición influyente en una coalición electoral victoriosa. La mayor cantidad de votos lograda por los nacistas fue en las elecciones municipales de 1937, en las que lograron 17.203 votos, llevando 151 candidatos, siendo elegidos apenas 14 nacistas. Mientras que en las elecciones parlamentarias, su más alta votación fue en 1937 con 17.253 votos -14.564 votos para diputados y 2.689 votos para senadores-, sumado al respaldo que dieron al candidato de derecha Alberto Moller. En Díaz, José. 2016. El movimiento nacional socialista o el nazismo con " $c$ ", Concepción, Editorial Escaparate, pp. 50-52, 55-56.

3 Para mayor referencia, se sugiere la investigación de Cristián Garay. Cfr. Garay, Cristian. 1990. El Partido Agrario Laborista, 1945-1958, Santiago de Chile, Editorial Andrés Bello.

4 Si bien es cierto Díaz Nieva plantea que las derechas habrían utilizado a los nacistas contra las izquierdas, cabría precisar si fueron las derechas en su conjunto, o solo los liberales. Las implicancias que tiene esta premisa tienen directa relación con el posicionamiento de los nacistas en el espectro derechista. En Díaz, José. 2016. El movimiento nacional socialista o el nazismo con " $c$ ", p. 48.
} 
A pesar de lo anterior, sí existe un volumen mayor -en comparación con los trabajos sobre el nacismo -de estudios y literatura sobre el nacionalismo ${ }^{5}$, el anticomunismo ${ }^{6}$, y el conservadurismo ${ }^{7}$. Estas investigaciones de inestimable valor, han aportado desde la historiografía ${ }^{8}$ hasta la crónica ${ }^{9}$, proponiendo una lectura del nacismo como fenómeno político. Específicamente se ha estudiado un acontecimiento trágico que marcó con sangre tan breve trayectoria política: la matanza del seguro obrero en $1938^{10}$.

Las múltiples referencias a "la torre de sangre" o los "mártires del 5 de septiembre"11 han contribuido a una construcción de imagen en torno a los nacistas, que varía entre la heroicidad -muy propia de los movimientos fascistas europeos-y la tragedia, esto último por las irónicas consecuencias del putsch enmarcado en el lento proceso que dio por finalizada la experiencia del nacismo.

Este estudio se alejará de la "torre de sangre" y sus connotaciones simbólicas, y se enfocará en el análisis de la doctrina del movimiento, a la luz de sus folletos oficiales, y de los documentos que elaboraron Jorge González Von Marées y Carlos Keller -principal líder e ideólogo respectivamente- desde la perspectiva de la nueva historia política.

No obstante los múltiples aspectos posibles de estudiar sobre la doctrina nacista, el objeto de análisis principal en este artículo será la concepción sobre el sujeto de cambio abordando aspectos sobre la militancia ${ }^{12}$, intentando dilucidar si estaba mediada por una condición de clase $^{13}$, nacionalidad o rol productivo ${ }^{14}$. Además se identificará y caracterizará la concepción

${ }^{5}$ Cfr. Ibíd. 2013. El nacionalismo en Chile: entre el fascismo y el autoritarismo conservador, Madrid, UNED, Tesis para optar al grado de Doctor en Historia.

${ }^{6}$ Cfr. Casals, Marcelo. 2016. La creación de la amenaza roja. Del surgimiento del anticomunismo en Chile a la "campaña del terror" de 1964, Santiago de Chile, Editorial LOM.

7 Cfr. Garay, Cristian. 2006. El Partido Conservador chileno, 1857-1966. Tendencias internas y conflictos doctrinarios, Madrid, UNED, Tesis para optar al grado de Doctor en Historia; Cfr. Ivulic, Jorge. 1997. Importancia del Partido Conservador en la evolución política chilena. Santiago de Chile, Universidad Bernardo O'Higgins.

8 Cfr. Moller, Magdalena. 2000. El movimiento nacional socialista chileno (1932-1938), Santiago de Chile, Pontificia Universidad Católica de Chile, Tesis para optar al grado de Licenciado en Historia.

${ }^{9}$ Cfr. Valenzuela, Emiliano. 2017. La generación fusilada. Memorias del nacismo chileno (1932-1938), Santiago de Chile, Editorial Universitaria.

10 Cfr. Anónimo. 1938. La verdad sobre los sucesos del 5 de septiembre de 1938, Santiago de Chile, Editorial Libertad; Cfr. Droguett, Carlos. 1953. 60 muertos en la escalera, Santiago de Chile, Editorial Nascimento; Cfr. Ibíd. 1939. Los asesinados del Seguro Obrero, Santiago de Chile, Editorial Ercilla; y el trabajo ya referido de Marcus Klein, Cfr. Klein, Marcus. 2008. La matanza del Seguro Obrero (5 de septiembre de 1938).

11 Calificativos referentes a la "matanza del seguro obrero" y los jóvenes nacistas fusilados.

12 Por militancia se entenderá la adscripción y compromiso político hacia una colectividad política. Independiente de lo anterior, la militancia como categoría, puede incluir aspectos como la cultura militante, el sujeto de cambio ya sea obrero, trabajador, asalariado, emprendedor, chileno, etc.-., como también las responsabilidades de un miembro de la organización.

13 Se entiende la complejidad del concepto "clase", principalmente por los aportes del historiador británico E. P. Thompson, que lo entiende como una categoría sociológica y cultural, desprendiéndolo de sus interpretaciones 
nacista sobre las organizaciones sindicales, y la propuesta política del rol de las organizaciones de trabajadores en la concepción de sociedad nacista.

Se utilizarán como fuentes los documentos partidarios, puesto que son recursos utilísimos para estudiar las posiciones doctrinarias, específicamente los folletos y libros de divulgación política. En efecto, los nacistas chilenos, en su búsqueda por mostrarse ante los otros como una alternativa válida -y de autodefinición ideológica- consideraron la producción intelectual como punto estratégico, independiente de los niveles de análisis y reflexión alcanzados. No obstante, es necesario precisar, que de forma oficial, al menos, quienes estaban detrás de gran parte de la producción intelectual del movimiento eran Jorge González Von Marées y Carlos Keller, sobre todo las fuentes que se utilizarán en este trabajo.

El estudio se basará en la trayectoria política del movimiento Nacional-Socialista, y no en la Vanguardia Popular Socialista ${ }^{15}$, colectividad que fue la heredera de los nacistas -los nacistas después de la "Matanza del Seguro Obrero" se rearticularon, y cambiaron su nombre a "Vanguardia..."- que representó la aparente izquierdización de la organización nacista, teniendo una efímera existencia. Esta aclaración es necesaria, puesto que gran parte de la escasa bibliografía existente suele incluir a la VPS como una segunda etapa del nacismo chileno -o como una etapa post-matanza del seguro obrero-. En este artículo no se estudiará esta segunda etapa, que amerita una investigación por si sola.

Sobre la problemática planteada, se establecerá como hipótesis de investigación que los nacistas habrían tenido una concepción integradora sobre el sujeto de cambio y la militancia, en función a criterios de nacionalidad, más que criterios de clase o de roles, ante lo cual su discurso buscaría concitar un apoyo transversal en la sociedad chilena, y en la composición de su propia militancia. En consecuencia, la concepción sobre las organizaciones de trabajadores recogería elementos del corporativismo, y una crítica a la concepción sindical marxista, que la harían dialogar más fluidamente con una concepción más integradora entre capitalistas y trabajadores, anatemizando la tesis de la lucha de clases, propia de la izquierda marxista.

Para llevar a cabo la exposición de esta investigación, se procederá a contextualizar el período de surgimiento del movimiento Nacional Socialista, buscar una caracterización de su

exclusivamente económicas, derivadas de una interpretación muy ortodoxa del marxismo. Cfr. Thompson, Edward. 2012. La formación de la clase obrera en Inglaterra, Madrid, Capitán Swing.

14 El rol productivo entendido como "clase" en su concepción marxista más clásica, es decir, el rol que tiene un sujeto en los medios de producción, tanto como poseedor de estos y del capital -burguesía-, o como poseedor de la fuerza de trabajo -proletariado-. Cfr. Marx, Carlos. 1946. El Capital, Buenos Aires, Editorial Tor.

15 Sobre el paso del Movimiento Nacional Socialista a la Vanguardia Popular Socialista, se sugiere consultar cfr. Valdés, Mario. "La transformación del Movimiento Nacional-Socialista de Chile en Vanguardia Popular Socialista. Su accionar político durante el Gobierno del Frente Popular: 1938-1941", en Revista Pencopolitana de Estudios Históricos y Sociales, Vol. 2, Concepción, pp. 55-84; Cfr. Robertson, Erwin. 1986. El Nacismo Chileno, Parral, Ediciones Nuestramérica. 
doctrina y despliegue histórico, para finalmente analizar las concepciones sobre el sujeto de cambio y las organizaciones de trabajadores.

Por la extensión propia del trabajo, se eludirá una contextualización continental e internacional del fascismo, centrando el foco de análisis en lo nacional. Por cierto, no se niegan las evidentes influencias externas de los nacistas, ni tampoco la ola de movimientos de idénticas características en América Latina y el mundo entero.

\section{Ibañistas y civilistas: pugna al interior de las derechas}

El movimiento nacional-socialista de Chile surge a comienzos de la década de los treinta, en un contexto general de crisis del capitalismo mundial, de incapacidad de la socialdemocracia de llevar a cabo una salida exitosa a dicha crisis, y de rearticulación de las organizaciones comunistas en el mundo. En el caso chileno no fue distinto, sin embargo un punto diferente fue que el "crack del 29"” no impactó a Chile bajo un gobierno democrático, ni tampoco socialdemócrata, sino bajo un régimen autoritario liderado por el general Carlos Ibáñez del Campo.

El colapso del régimen provocó entre sus adherentes una dispersión, en la cual cada uno de ellos buscó un espacio en donde desplegarse políticamente. Algunos se vincularon a la izquierda y otros a las derecha. Este último punto es importante, puesto que el ibañismo -no necesariamente Ibáñez- tuvo estrecha vinculación con el surgimiento de los nacistas.

No obstante, cabe preguntar la procedencia y posicionamiento en el espectro político fundacional de los nacistas, desde qué domicilio político provenían, y con ello, desde dónde se proyectaron; ¿Podríamos situarlos en la derecha política? Esta pregunta no es baladí, ya que dependiendo de la respuesta, implica partir de determinadas premisas:

1. Si se sitúa en la derecha, su conflicto con el liberalismo podría circunscribirse en una disputa por la representación del espectro derechista; a su vez, esa disputa podría entenderse desde el conservadurismo extremo, o una tercera posición entre conservadurismo y liberalismo. Este punto explicaría la razón de por qué sus mayores críticas van hacia la izquierda $^{16}$, a la que calificaban en todas sus múltiples expresiones como marxista. Así también explicaría la concepción meritocrática, e inclusive jerárquicamente estructurada de la sociedad y de los países ${ }^{17}$.

\footnotetext{
16 León, René. 1971. Evolución histórica de los Partidos Políticos Chilenos, Buenos Aires, Editorial Francisco de Aguirre, p. 137.

17 González, Jorge. 1936. Pueblo y Estado, Santiago de Chile, Imprenta y Litográfica Antares, p. 3. En este discurso pronunciado por "el jefe" Jorge González Von Marées, pasa revista a sus concepciones teóricas, e inclusive históricas sobre el desenvolvimiento de la humanidad. En este escrito es donde son más claras las influencias del intelectual Osvald Spengler. Para ambos, las sociedades también pueden morir, y prevalecen las más fuertes, inclusive siendo destinadas al éxito y la gloria de la historia.
} 
2. Si se posiciona a los nacistas desde una visión muy particular de la izquierda, tendrían sentido ciertas visiones estatistas y un ethos ligado al altruismo y el desprendimiento material, sin embargo, este estaría supeditado al Estado, como representación de la voluntad nacional no popular- el cual se acepta que esté gobernado por unos pocos ${ }^{18}$, bajo el mandato de una estructura moral rígida ${ }^{19}$. Ante todo, los nacistas buscan una nueva y regenerada $-\mathrm{y}$ patriótica- aristocracia ${ }^{20}$.

3. Si los nacistas se entienden desde la superación del eje izquierda-derecha, y a las posiciones ideológicas y doctrinas ${ }^{21}$, esto explicaría la crítica virulenta al sistema de partidos ${ }^{22}$, y la concepción de crisis y corrupción generalizada de los ideales y la política, punto planteado especialmente por los dos líderes del movimiento: Jorge González Von Marées y Carlos Keller. No obstante cabe preguntar: ¿A qué respondía la idea de superación del posicionamiento en el espectro? ¿A una concepción ideológica que no podía ser codificable en la clave izquierdaderecha? ¿A desmarcarse de una clasificación que podía perjudicar su popularidad en ciertos sectores de la sociedad? ¿O a un intento por superar las izquierdas y derechas?.

Sobre la pregunta que se ha planteado, en este trabajo se concebirá al movimiento nacional socialista ${ }^{23}$ como una reacción muy particular de la derecha chilena, que ya no se sentía interpretada por los partidos históricos -Conservador y Liberal- y que veía cómo sus intereses de clase estaban siendo amenazados por un capitalismo en crisis que abría las posibilidades de crecimiento del movimiento obrero y de los partidos marxistas. Sobre la extracción de clase del movimiento, José Díaz plantea que este estaría conformado por las "clases adineradas acomodadas" 24 .

No obstante, se advierte lo complejo del ideario nacista, debido a que la base ideológica que los impulsó primordialmente fue un nacionalismo -conservador por cierto- en cierta forma transversal en el espectro político, que les permitió inclusive comulgar con ciertas ideas muy propias de las izquierdas ${ }^{25}$, sin necesidad de abandonar posiciones conservadoras referentes a la tradición y la sociedad ${ }^{26}$.

\footnotetext{
18 González, Jorge. 1936. Pueblo y Estado, pp. 5, 6.

19 Jobet, Julio César. 1955. Ensayo crítico del desarrollo económico-social de Chile, Santiago de Chile, Editorial Universitaria, p. 195.

20 González, Jorge. 1936. Pueblo y Estado, pp. 6-7.

21 Ibíd. 1932. La concepción nacista del Estado, Santiago de Chile, Imprenta La Tracción, pp. 8-9.

22 lbíd., p. 8.

${ }^{23}$ Movimiento Nacional Socialista de Chile.

24 Díaz, José. 2016. El movimiento nacional socialista o el nazismo con "c", p. 19.

25 El nacionalismo como plataforma común de colectividades de izquierdas y derechas, tiene como el más icónico ejemplo los proyectos de nacionalizaciones, e inclusive el desarrollo y empuje de industrias nacionales. Décadas después, en los años setenta, uno de los ejemplos más icónicos de lo anterior fue la "nacionalización del cobre", cuya ley fue apoyada tanto por el MIR como Patria y Libertad. Sobre las cercanías y distancias en propuestas políticas, se sugiere consultar el "Programa" del Partido Socialista y "Declaraciones fundamentales, plan de acción,
} 
Además, la concepción estatista que fácilmente podría ser identificada bajo códigos propios del fascismo e inclusive del sovietismo ${ }^{27}$, también sería entendible bajo el ideario nacionalista, e inclusive ibañista, por la dirección económica que le dio el general Ibáñez al país durante su régimen, definida como "nacionaldesarrollismo".

A su vez, la pugna entre conservadores y liberales, de la cual los nacistas no estuvieron ajenos proponiendo un tercer camino al interior de las derechas, no fue el único ni el primer punto de divergencia que explicó y justificó su existencia. Existió un aspecto aún más relevante que separó aguas y que tuvo un rol clave en sus posiciones políticas: las visiones ibañistas ${ }^{28}$ y civilistas $^{29}$ en la derecha chilena.

El carácter coyuntural del civilismo tiende a eludir u omitir un debate más profundo al interior de las derechas, referente a la aceptación de un gobierno autocrático y dictatorial, o un presidencialismo fiscalizado por un Congreso y bajo una democracia liberal. Evidentemente la figura del hombre fuerte, tanto providencial como líder, fue parte de la racionalidad de las derechas chilenas. Pero el régimen ibañista tensó al extremo esta divergencia provocando la fundación del civilismo, entendido como un movimiento que no tenía como objetivo más que devolver el gobierno a los civiles.

El respaldo político y rol que tuvieron personas, tanto militantes como independientes de derechas, generó cuestionamientos en este lado del espectro, tanto al inicio del régimen en 1927 -ya que Ibáñez desplazó a un presidente de derecha- como en su ocaso en 1931, debido a que el dictador llevó a cabo medidas sociales ligadas a leyes referentes al trabajo sin perjuicio que persiguió a sindicalistas- como medidas económicas de carácter nacionalista -incipiente industrialización ${ }^{30}$ - que dejaron en entredicho la creciente tendencia mancuriana de los economistas liberales. Pues claro, el carácter autocrático de Ibáñez no implicó un problema terminal que separara aguas entre las derechas y el gobierno, tal como lo demostró

organización, programa" del Movimiento Nacional Socialista, específicamente los puntos sobre industrialización a manos del Estado. Cfr. Partido Socialista. 1936. Programa, Santiago de Chile, Departamento de Publicaciones PS; Cfr. Movimiento Nacional Socialista. 1932. Declaraciones fundamentales, plan de acción, organización, programa, Santiago de Chile, Imprenta La Tracción.

${ }^{26}$ Sin embargo, el diálogo cada vez más fluido con las izquierdas, a finales de la década de los treinta, produjo una tensión insoslayable entre nacionalismo y conservadurismo, que finalmente quebró el movimiento.

${ }^{27}$ A pesar de que la predominancia del Estado podría ser un punto de encuentro entre las dos posiciones descritas, existen evidentes diferencias, entre ambas sobre la problemática del "Estado", ya que mientras el fascismo fue cercano a un capitalismo de Estado, en el cual dicha superestructura representaba para ellos el "alma nacional"; en el sovietismo -socialismo soviético- se implementó un socialismo de Estado, y este representaba una estructura que debía ser superada. Si bien es cierto, ciertos códigos y nociones sobre el rol del Estado en la sociedad pudieran llevar a pensar la confluencia entre ambas posiciones, advertimos el riesgo de homologarlas.

28 Ibíd., p. 6.

29 Jobet, Julio César. 1955. Ensayo crítico del desarrollo económico-social de Chile, p. 180.

30 Salazar, Gabriel; Pinto, Julio. 2002. Historia contemporánea de Chile III. La economía: mercados, empresarios y trabajadores, Santiago de Chile, LOM Ediciones, p. 76-77. 
el beneplácito y agrado que demostraron los parlamentarios derechistas designados a dedo bajo el Congreso Termal. La nula protesta pública de las colectividades da muestra de aquello, salvo casos puntuales de militantes concretos -ligados a la Juventud Conservadora y el Partido Radical- que denunciaron el carácter antidemocrático de dicho Congreso y no se sumaron, condenándolo ${ }^{31}$.

Las contradictorias medidas del dictador, bajo la única clasificación posible ligada al nacionalismo, le hizo ganar adeptos y detractores en ambos lados del espectro. En el caso de las derechas ${ }^{32}$, como hemos expuesto, fue completamente problemático adscribir al ibañismo o no, aún más definir por completo a las derechas como ibañistas o civilistas ${ }^{33}$. Por lo que para zanjar esta discusión, se propone partir de que la noción de un gobierno que defendiese a la oligarquía dotándola de un rol social bien definido y la aceptación de una sociedad de clases, fue la base de consenso entre las diversas tendencias de las derechas, no así los aspectos económicos que se debatían entre un capitalismo de Estado alentado por un desarrollismo nacionalista ${ }^{34}$, y por otro lado, una defensa de la economía de libre mercado mancuriana ${ }^{35}$.

Otro punto que es preciso agregar a la bifurcación de las derechas, tiene relación con el sistema político defendido, puesto que mientras algunos consentían un gobierno autocrático e inclusive dictatorial -la figura de Diego Portales fue fuertísima- el otro sector era un

\footnotetext{
31 Uno de los que renunció en las postrimerías del régimen ibañista a su cargo como diputado del Congreso termal fue Gabriel González Videla. En González, Gabriel. 1975. Memorias. Tomo I, Santiago de Chile, Editora Gabriela Mistral, p. 105.

32 Un claro ejemplo de la visión de las derechas opositoras a Ibáñez, es Alfredo Guillermo Bravo. En su libro 4 de junio: festín de los audaces, junto con criticar a la República Socialista de Grove, lanza ácidos cuestionamientos y reproches a Ibáñez y su camarilla liderada por Carlos Dávila. En Bravo, Alfredo. 1932. 4 de junio: festín de los audaces, Santiago de Chile, Empresa Letras, pp. 114-118.

33 El civilismo también lo entendían como un movimiento, tal como deja entrever Manuel Aránguiz en su libro referido al golpe de Estado del 4 de junio de 1932, en el cual acusa al civilismo de tener una actitud pasiva ante el movimiento revolucionario que lideró el comodoro Marmaduke Grove contra Juan Esteban Montero, el cual es sindicado como uno de los civilistas más insignes. Independiente de lo anterior, fue Ministro del Interior durante el régimen ibañista. En Aránguiz, Manuel. 1933. El 4 de junio, Santiago de Chile, Empresa Zig-Zag, p. 30. Sin embargo, el mismo movimiento del 4 de junio de 1932, puso de manifiesto la dicotomía entre civilismo y "militarismo", ya que los adeptos a Montero, exhortaban a la defensa del gobierno en nombre del movimiento civilista, tal como refiere Aránguiz parafraseando a Orrego Puelma: "Ante la negativa de cooperación de los señores Barros Jarpa y Fajardo, yo declaro, solemnemente ante el país, que son culpables de traición a la República y al Civilismo.". En lbíd., p. 36.

34 Tomás Moulián en su libro Fracturas los denomina como "doctrinarios", sin embargo en el trabajo de Gabriel Salazar y Julio Pinto califican las políticas económicas del segundo gobierno de Alessandri -y con ello a su Ministro de Hacienda, Gustavo Ross- como "keynesianismo larvado y anticipado...". En Moulián, Tomás. 2006. Fracturas. De Pedro Aguirre Cerda a Salvador Allende (1938-1973), Santiago de Chile, LOM Ediciones, p. 29; Salazar, Gabriel; Pinto, Julio. 2002. Historia contemporánea de Chile III. La economía: mercados, empresarios y trabajadores, p. 78.

35 También se ha tildado a este grupo de "ortodoxos" -o liberales ortodoxos-. En Moulián, Tomás. 2006. Fracturas. De Pedro Aguirre Cerda a Salvador Allende (1938-1973), pp. 29, 34.
} 
defensor irrestricto de la democracia liberal, la cual iba en perfecta sintonía con la economía de libre mercado.

Esta tensión de resolvió en dos posturas concretas: los defensores del desarrollismo y el gobierno autocrático que fueron la base de sustentación política del dictador, conocidos como ibañistas; y quienes, en consecuencia a sus ideales políticos y económicos buscaron una salida legal -y pacífica- al régimen, para retomar la senda de la democracia liberal, también conocidos como civilistas, cuyo nombre se debe a la idea del retorno de un civil al gobierno en claro detrimento de Ibáñez, un militar.

Sectores ibañistas fueron parte de la base de sustentación política del movimiento nacista, quienes se sintieron en orfandad con el exilio autoimpuesto por lbañez una vez caído su régimen. Pero su adhesión no fue permanente. Años más tarde -a finales de la década de los treinta- los nacistas fueron críticos de lbáñez $z^{36}$ y de algunas determinaciones políticas, como los constantes vaivenes del dictador, muy solícito con izquierdas y derechas con el objeto de alcanzar el poder bajo un mecanismo de elección democrático. Este punto fue imposible de perdonar para los nacistas, pues claro, la adhesión como ibañistas al líder fue más allá de la persona misma, sino de los ideales que representaba, y la idea de nación que defendía. Si se tuviera que posicionar a los nacistas entre ibañistas y civilistas, a pesar de que ellos se planteaban como una alternativa más, sin lugar a dudas estaban más cercanos al ibañismo, por compartir el mismo ideal de gobierno, como también el nacionalismo económico.

En definitiva, la divergencia al interior de las derechas entre civilistas e ibañistas ${ }^{37}$ es un antecedente clave -desde el punto de vista local- del surgimiento de los nacistas, ya que gran parte de los segundos, enarbolando las banderas del nacionalismo, no se sintieron interpretados por los partidos existentes después de caído el régimen ibañista. El nacionalismo daba para todo y para nada. Es por esto que gran parte de los adeptos al dictador, liberales descontentos, y diversas personalidades que tenían cercanías al fascismo europeo $^{38}$, dieron vida al movimiento Nacional Socialista de Chile en 1932.

\footnotetext{
36 “El período de Ibáñez fue, indudablemente, de un extraordinario progreso material para el país, pero faltó en él una concepción clara de la tarea de reconstrucción espiritual por realizar. Ibáñez quiso reconstituir el Estado, pero olvidó que al mismo tiempo era necesario reconstituir el pueblo. A esto se debió su fracaso y el que después de su caída el país haya continuado por el despeñadero." En González, Jorge. 1936. Pueblo y Estado, p. 6.

37 Aránguiz también refiere -parafraseando a Héctor Orrego Puelma- a un momento decisivo al interior de las derechas, en las cuales se exigió poner de manifiesto la defensa de lo civil, o de lo militar, en el contexto del derrocamiento del presidente Juan Esteban Montero. En Aránguiz, Manuel. 1933. El 4 de junio, p. 35.

38 Sobre este punto, Robertson plantea que Keller se distancia del fascismo, y esto no es menor, ya que podría explicar las distancias del principal ideólogo con González o con el resto del movimiento, e inclusive con otras colectividades filo-fascistas como Acción Nacionalista de Chile, y personajes como Juan Gómez Millas. En Robertson, Erwin. 1986. El nacismo chileno, Parral, Ediciones Nuestramérica, p. 24; Cfr. Díaz, José. 2016. El movimiento nacional socialista o el nazismo con " $c$ ", p. 25.
} 


\section{2: se funda el MNS... iChilenos a la acción!}

La irrupción de los nacistas en el sistema de partidos chileno se dio en un momento donde el general Ibáñez estaba un tanto ajeno de la escena política, buscando sus prosélitos que regresara al poder. Aún más, el año 1932 marcó el inicio de la recomposición democráticoliberal del sistema político chileno, de la mano del enemigo jurado del militar: Arturo Alessandri Palma. La misma elección del político liberal, respondió a una crítica a los sucesivos gobiernos que se dieron lugar en el mismo año 32, como también una recomposición de las clases dominantes duramente cuestionadas durante dicho año por las izquierdas.

El león de Tarapacá -apodo de Alessandri- ya no era el político populista que lanzaba duras consignas contra la "canalla dorada" -las clases dominantes- ni a favor de la "chusma querida" -el proletariado- como lo hizo en los años veinte. Ahora "el león", claramente mucho más conservador, tendió hacia una política más proclive a posiciones librecambistas. Esto al interior de las derechas suscitó un apoyo generalizado, más allá de ciertas críticas que buscaron matizar ciertos derroteros que Alessandri iba trazando -los liberales y la crítica a Gustavo Ross, ministro de Hacienda; y la Juventud Conservadora y la crítica a la falta de políticas sociales-. Sin embargo, hubo un sector de las derechas que durante este gobierno no vieron a alguien que los representara: ellos fueron los nacistas.

El movimiento Nacional-Socialista de Chile se fundó el 5 de abril de 1932 en medio de altas expectativas en los círculos nacionalistas, pero con la indiferencia absoluta del resto del espectro político. Esta situación no cambió mucho en los primeros meses, siendo posteriormente revertida por tres elementos que se conjugaron constantemente durante la década de los treinta: el ascenso de los fascismos europeos, conquistando el gobierno en Alemania e Italia -logrando tensar el sistema de partidos chileno ${ }^{-39}$, la militarización de la sociedad chilena, y por último, el rechazo y animadversión que propagó el Partido Socialista y el resto de las izquierdas, hacia el nacismo.

Las ciudades en donde hubo más militantes al interior del nacismo fueron: Santiago, Valparaíso, Concepción-Talcahuano y Temuco. Las características geográficas y sociales explicaron la importancia del nacismo en estas ciudades. Santiago era la ciudad capital, y concentraba a las clases medias -más proclives al nacionalismo- y profesionales -que tenían mayor acceso a la literatura fascista y las noticias de Europa-; las ciudades de Valparaíso y la conurbación Concepción-Talcahuano poseían los dos principales puertos del país, lugares a los cuales llegaban gran parte de los extranjeros, teniendo un trato fluido con alemanes e italianos que estaban imbuidos de las nuevas doctrinas corporativistas contingentes en Europa; y Temuco -y el sur en general- constituían uno de los principales epicentros en el sur

39 Dávila, Carlos. 1950. Nosotros, los de las Américas, Santiago de Chile, Editorial del Pacífico, pp. 87, 124-125. 
-junto con Valdivia y Osorno- de la colonización alemana, y conflicto indígena, que exacerbó el carácter racista de ciertos inmigrantes europeos.

Durante las elecciones de 1937, el nacismo logró elegir a tres diputados: Jorge González Von Marées, Fernando Guarello y Gustavo Vargas Molinare. Las ciudades en que fueron electos no son casualidad, González en Santiago, Guarello en Valparaíso y Vargas en Temuco.

Otro elemento a considerar es que esta organización nunca se consideró como partido, sino como movimiento ${ }^{40}$. Quien estaba a la cabeza del mismo, era Jorge González ${ }^{41}$ proclamado como el "jefe"- ${ }^{42}$. Dos de las principales razones que explican el carácter de movimiento era que los nacistas tenían una visión sumamente crítica de los partidos, en particular el carácter clientelar y corrupto que asumían, muy propio del sistema económico y político deficiente en el Chile de primera mitad del siglo XX; la otra razón radicaba en la autoconcepción de la propuesta política que estaban levantando: un sentimiento nacional de disconformidad hacia el liberalismo y el marxismo, que buscaba recuperar la nacionalidad y defender la espiritualidad propia de la civilización occidental y cristiana ${ }^{43}$.

\section{Movimiento Nacional... ¿Socialista? Vinculación con el socialismo}

La conformación del ideario nacista, y la construcción de su doctrina, no dejó de ser conflictiva, tomando elementos tanto teóricos como éticos, que muchas veces no tenían coherencia entre sí. Dentro de estas contradicciones se sitúa la denominación misma del movimiento, y con ello, su adscripción doctrinaria. ¿Tiene acaso algo de problemático la definición de nacional socialistas? Pues claro ¿Qué de socialistas tenían los nacistas?

González Von Marées y Keller, como líderes nacistas, dilucidaron este punto, estableciendo que el nacismo era socialista, en tanto buscaba que todas las actividades económicas estuvieran dirigidas hacia un bien común, o como ellos llamaban "función social”4" dejando a un lado la concepción del lucro individual.

\footnotetext{
40 Movimiento Nacional Socialista de Chile. 1932. Declaraciones fundamentales, plan de acción, organización, programa, Santiago de Chile, p. 16.

41 Sobre Jorge González Von Marées, Ricardo Boizard tiene una particular descripción: “Como quiera que sea, no es la oratoria de González Von Marées (oratoria fría, abstracta, conceptuosa) lo que caracteriza a los jefes nazistas y fascistas en que se inspira. (...) A veces hemos pensado que González Von Marées fué(sic) más escuchado en la Cámara por la explotación del escándalo que por el interés a sus discursos. La amenidad no la daba el orador, sino sus víctimas.". En Boizard, Ricardo. 1948. Voces de la política. El púlpito y la calle, Santiago de Chile, Editorial del Pacífico, pp. 40, 41.

42 Jobet, Julio César. 1955. Ensayo crítico del desarrollo económico social de Chile, p. 196.

43 Moller, Magdalena. 2000. El movimiento nacional socialista chileno (1932.1938), pp. 17, 18, 21.

44 Movimiento Nacional Socialista de Chile. 1932. Declaraciones fundamentales, plan de acción, organización, programa, p. 18.
} 
Es en definitiva la supeditación de los intereses individuales, en función de los colectivos, y ellos deben ser encauzados por el Estado. Este, a su vez, tiene el rol rector del avance económico de la sociedad, teniendo las facultades de exigir la eficiencia en la producción, y "reprimir las degeneraciones y vilezas del capitalismo parasitario y reducir el dinero a su sana función de instrumento de producción y de progreso" ${ }^{45}$.

La noción orgánica del Estado, al entenderlo como un ser viviente que existe y también muere, fue muy propia de los nacistas ${ }^{46}$, no obstante cabe preguntar, ¿qué tan socialistas eran sus concepciones ideológicas y políticas? Esto tiene estrecha relación con la noción de socialismo que se tenía en Chile durante la primera mitad del siglo XX.

El ingreso de las ideas -o ideologías- de redención social ${ }^{47}$ a finales del siglo XIX y comienzos del XX se caracterizó por su vastedad, pero también por la nula regulación de la ortodoxia textual. Es decir, las traducciones de textos en otros idiomas que no fuera el español carecían de rigor, proliferaron las editoriales que eran perseguidas por la propaganda escrita que levantaban, la incomprensión de las doctrinas que exponían en los textos, y la tergiversación. En fin, era difícil dilucidar que la producción intelectual en Chile, y la que llegaba -muchas veces de contrabando- desde el extranjero, fuese coherente a las fuentes o nociones socialistas originales. Es decir, a Chile llegaban y se producían interpretaciones del socialismo, que no necesariamente expresaban lo que el socialismo era. Es por esto que, durante la primera mitad del siglo XX, podemos establecer que la noción de socialismo era más bien genérica ${ }^{48}$.

Por ende, no era difícil imaginar que pudieran existir sectores nacionalistas -y populistasque se situaran bajo el rótulo de "socialistas", entendiendo como socialismo la concepción de que el control de la economía debía estar regido por la sociedad, la que con distintos mecanismos -Estado, mutuales, sindicatos, etc.- llevase a cabo sus propósitos. Evidentemente, desde esta definición, los nacistas no entraban en contradicción con otras doctrinas socializantes, no así con la postura de quién debía controlar el Estado. ¿Acaso una

\footnotetext{
45 Ibíd., p. 19.

46 Sobre la concepción nacista del mundo y la sociedad, Ricardo Boizard ironiza refiriéndose a González Von Marées: "Cada nacista se ha sentido atraído por este hombre de sinceridad, cosa que nadie puede discutírsela ni negársela. El(sic) cree firmemente que la sociedad actual está envenenada en sus cimientos. Cree que la civilización en que vivimos llegó al límite de la decadencia. Afirma que solo una gran labor creadora podrá levantar de sus cenizas al hombre y que solo el nacismo será capaz de esta labor creadora. Se encuentra íntimamente convencido de su vocación política y no comprende que se pueda vivir en nuestro país al margen de su voluntad. Una fe(sic) tan firme y tan exteriorizada, naturalmente conmueve y sugestiona aunque la elocuencia no sea tan perfecta como esa fe(sic).". En Boizard, Ricardo. 1948. Voces de la política. El púlpito y la calle, p. 42.

47 Concepto de utiliza el historiador Sergio Grez para denominar a las ideologías emancipatorias. En Grez, Sergio. 2011. Magno Espinoza. Pasión por el comunismo libertario, Santiago de Chile, Editorial USACh, p.19.

48 Venegas, Diego. 2017. Una relación dialéctica. Socialistas y comunistas en Chile (1933-1948), Chillán, Universidad del Biobío, Tesis para optar al grado de Magíster en Historia de Occidente, p. 63.
} 
vanguardia revolucionaria, un consejo obrero, o una aristocracia responsable? Los nacistas se inclinaron por esta última opción ${ }^{49}$.

Otro aspecto problemático fue su vinculación con el fascismo. Sobre este punto no solo Robertson plantea la presencia de rasgos fascistas y la distancia de esto con el ideólogo principal, Carlos Keller, sino que Díaz Nieva concibe al nacismo como un "movimiento de matices fascistas" ${ }^{\prime 50}$. Lambert por su lado, separaría aguas entre el nacismo y las posiciones reaccionarias y conservadoras ${ }^{51}$. ¿Acaso podríamos entender el nacismo como una agrupación revolucionaria nacionalista? ${ }^{52}$.

Elementos que permiten clarificar este punto son las propuestas políticas y concepciones de la sociedad, las cuales permiten que se pueda posicionar al nacismo como una agrupación fascista, o cercana a ello. Si bien es cierto, los nacistas apelaron a una construcción auténtica de sus elementos políticos y teóricos, no fueron ajenos a las influencias, tanto nacionalistas como propiamente fascistas.

La construcción de la doctrina nacista y su concepción de la sociedad tuvo dos aspectos que se procederán a analizar: cuál era para ellos el sujeto de cambio, y en consecuencia, a quienes dirigían su acción política para captar militantes -según criterios de clase, nacionalidad o rol productivo-y por otro lado, el rol de las organizaciones de trabajadores en la futura sociedad nacista.

\section{La concepción nacista de la sociedad (I): construcción del sujeto de cambio y del militante}

Para ir descomponiendo y estudiando la doctrina nacista es necesario partir por la misma visión que tenían de la sociedad chilena, tanto de su presente, futuro y pasado. En este último punto, los nacistas fueron prolíficamente críticos de la historia nacional.

Esta se resume en los siguientes puntos: 1. La independencia de Chile como una gesta heroica que demostraría la vocación de grandeza del pueblo chileno. Dicho acontecimiento habría sido eclipsado por el surgimiento de caudillos -O'Higgins, Carrera y Freire- con intereses individuales, que demostrarían la inmadurez política de la primera etapa de vida de la República, sumiendo al país en una anarquía, producto de la carencia de un Estado ${ }^{53}$; 2 . La llegada de Portales al gobierno significaría la maduración del pueblo chileno, y además, se trataría del único político que fue capaz de encauzar al país al éxito, sentando las bases de un Estado robusto. Bajo su liderazgo la aristocracia y los sectores dominantes de la sociedad

\footnotetext{
49 Tal como plantea Robertson, una "minoría selecta”. En Robertson, Erwin. 1986. El Nacismo chileno, p. 42.

50 Díaz, José. 2016. El movimiento nacional socialista o el nazismo con "c", pp. 75-76.

51 lbíd., p. 77.

52 Tal como se definió décadas después el Frente Nacionalista Patria y Libertad. Cfr. Rodríguez, Pablo. 1971. Manifiesto Nacionalista. Frente Nacionalista Patria y Libertad, s/e.

53 González, Jorge. 1936. Pueblo y Estado, p. 4.
} 
chilena habrían demostrado sobriedad y visión de país, y los sectores populares habrían sido educados para su misión de servir al Estado. Esto habría tenido como resultados la gloria económica, política y militar -victorias en las guerras contra la Confederación Perú-Boliviana y del Pacífico-, aún a costa de la vida de Portales, el cual se habría inmolado por la gloria de la patria, debido a su asesinato ${ }^{54} ; 3$. La época portaliana habría llegado a su fin, de la mano de su éxito militar. La llegada de grandes cantidades de dinero, producto de la victoria militar contra las naciones adyacentes, habría corrompido la aristocracia chilena, volcándola en un sector egoísta y centrado en el enriquecimiento personal, y no nacional. Bajo este escenario, la aristocracia habría asesinado al último portaliano: el presidente José Manuel Balmaceda en la guerra de 1891. De ahí en adelante, los sectores dominantes habrían gobernado sin una visión nacional, sino individual, y sin contrapeso. Ya en la década de los veinte quien habría puesto en tela de juicio esta situación habría sido el presidente Arturo Alessandri, intentando dejar atrás la "época corneliana" ${ }^{55}$, pero su carácter de caudillo habría de superarlo. Ante lo cual, los militares habrían entrado en escena, y fieles a los más hondos sentimientos portalianos, liderados por Carlos Ibáñez del Campo, habrían recuperado para Chile la gloria, el progreso material, y la visión de destino. Sin embargo, la inexperiencia política de los militares e Ibáñez, habría facilitado su caída, y con ello el regreso de la época de los caudillos y los "cornelios"

En conclusión, la historia de Chile transitaría en una honda crisis no solo económica, sino también de visión de destino nacional, y una crisis espiritual, que de una forma u otra, minaría las bases espirituales y materiales de la cultura cristiana en Chile ${ }^{57}$. Bajo esta lectura de la trayectoria histórica de Chile, los nacistas intentaron justificar su ingreso a la historia y su propuesta política, más aún, hasta les permitió realizar una lectura de la situación política de su tiempo presente, tal como expuso Jorge González:

“Portales, en 1830, tuvo a su disposición un pueblo y sobre todo, una magnífica aristocracia, de modo que su labor se limitó a dar vida a un Estado para dirigir a aquel pueblo. Hoy, en cambio, falla el pueblo y falla el Estado. (...) Hoy carecemos en Chile de una aristocracia selecta, consciente de su misión y de sus deberes; en su lugar solo existe una plutocracia sórdida y corrompida, dominada por una insaciable sed de lucro y cuyos hábitos depravados de vida constituyen la mejor demostración de cómo el comunismo ha penetrado en el corazón de la sociedad chilena" ${ }^{58}$.

\footnotetext{
54 Ídem.

55 La época "corneliana" fue llamada por el político Cornelio Saavedra, sindicado como un ejemplo del político preocupado de la ganancia personal, avaro y mediocre. En Ibíd., pp. 5-6.

56 Ibíd., pp. 4-5.

57 Corvalán, Luis. 2015. "Identidad, ideología y política en el Movimiento Nacional Socialista de Chile, 1932-1938", en Izquierdas, № 25, Santiago de Chile, p. 88.

58 González Von Marées, Jorge. 1936. Pueblo y Estado, p. 6.
} 
En función de lo anterior, los nacistas conciben una sociedad estratificada en clases, pero no bajo una interpretación canónica desde el marxismo que la entiende desde un antagonismo, sino desde la perspectiva de la colaboración y la responsabilidad de clases ${ }^{59}$. Pues claro, los nacistas entienden al individuo como un "servidor del Estado" ${ }^{60}$, propio de la noción de socialismo que tenían, y de una ética que se basaba en la disciplina. La aristocracia debía tener un alto sentido de su misión histórica, y una ética acorde al desafío de regir los destinos del país. Bajo esa lectura los nacistas proponían crear una nueva aristocracia ${ }^{61}$ que tenga interiorizada la honestidad y la justicia social. Consideraban que los más idóneos para llevar a cabo el recambio de la aristocracia eran sus cuadros, ya que según ellos, solo los militantes nacistas tendrían las virtudes que están definidas por el amor al trabajo, una actitud abnegada -o espíritu de sacrificio como ellos lo denominan- honestidad y patriotismo.

En el caso del pueblo -o masas populares, otro calificativo que utilizaban- el nacismo tenía dos principales nociones: sus deberes y sus derechos.

Este punto es interesantísimo, puesto que identificaban dentro de las masas populares los diversos oficios y profesionales que podían existir en la época, por ende, dentro de este grupo podían estar circunscritos tanto obreros, como abogados, científicos, y otras disciplinas y empleos. La visión de disciplina social muy arraigada en la concepción nacista de la sociedad y de las clases sociales, les permitió establecer responsabilidades concretas a cada rubro y área productiva, las que coordinadas y compenetradas darían curso al desarrollo económico nacional, es por ello, que los nacistas consideraban que los diversos trabajadores debían "honrar" a sus respectivos trabajos, tal como mencionaban: "No es el puesto el que debe prestigiar el puesto. Lo esencial no es ser obrero, ser abogado o ser político, sino que saber ser obrero saber ser abogado saber ser político. Saber serlo y tener orgullo de serlo"62.

Es así que las masas populares, al prestigiar sus respectivos puestos de empleo, servían al Estado, formando y dándole vida.

Cada clase debía cumplir una función, de la cual emanaban deberes concretos: la aristocracia tenía el deber de gobernar; y las masas populares el deber de ser gobernados, producir y servir al Estado. En este sentido, los nacistas tenían una lectura de la sociedad que les permitió identificar dos principales clases bien definidas, no obstante a diferencia del marxismo, no buscaron subvertir el orden de clase, sino darle un sentido y una misión.

\footnotetext{
59 Díaz, José. 2016. El movimiento nacional socialista o el nazismo con "c", pp. 20-21.

60 Movimiento Nacional Socialista de Chile. 1932. Declaraciones fundamentales, plan de acción, organización, programa, p. 19.

61 González Von Marées, Jorge. 1936. Pueblo y Estado, p. 6.

62 Los nacistas constantemente reafirmaban el rol social que tenía cada una de las áreas productivas, propio de su visión orgánica del Estado muy propia de las spenglerianas. En Ibíd., p. 19. Las negritas son parte del texto citado.
} 
Sin perjuicio de lo anterior, el sujeto de cambio, aquel que habría de construir la sociedad nacista no sería una clase determinada, a pesar de que tenían una concepción claramente estratificada, sino el impulso de cambio estaría sujeto al propio pueblo chileno, a la nacionalidad, la cual asumiendo sus diferencias de clase, y las responsabilidades inherentes a las condiciones sociales y económicas, colaboraría estrechamente como un solo cuerpo, para construir la sociedad nacista. Esto explica el carácter pluriclasista del mismo movimiento, existiendo en su seno, una reproducción de su misma concepción de sociedad, alcanzado el liderazgo los militantes de sectores más acomodados, como el mismo González Von Marées y Keller.

Sin embargo, ¿a quién cabía la responsabilidad de liderar el proceso, y de estar por sobre la "minoría selecta"? ¿Acaso un dictador o un caudillo? Evidentemente, la crítica al sistema de partidos, y la historia inmediatamente precedente al surgimiento del nacismo, habían tenido presencia tanto de dictadores -como Ibáñez- y caudillos -como Alessandri- que según los nacistas, gobernaban para sí $^{63}$. ¿Qué proponían entonces? La figura del "jefe", el cual representaba un símbolo ${ }^{64}$, de la nacionalidad y de la idea fuerza del nacismo. Había en esta figura un liderazgo no solo político, sino también espiritual.

Complementando este punto, Erwin Robertson plantea que la concepción de Estado en el nacismo criollo sería independiente de todo interés clasista, y se levantaría como una organización completamente autónoma de las fuerzas de trabajo ${ }^{65}$. La pertinencia del concepto "clase" o no, podría llevar a múltiples interpretaciones sobre el ideario nacista. Por lo mismo, es necesario explicitar que el uso del concepto clase en los documentos nacistas, más que compartir una concepción marxista, apela a una identificación de las diversas áreas productivas, profesiones y oficios -el uso del concepto "gremio", que más adelante se analizará- es decir, los nacistas identifican una segmentación de la sociedad, no de forma crítica, ni tampoco reducida exclusivamente a su rol y/o apropiación de los medios de producción, sino desde el punto de las responsabilidades políticas y sociales, y su acción orientada a buscar prosélitos, iba en la misma dirección: dirigentes y dirigidos, ingenieros y obreros, médicos y enfermeros, intelectuales y profesores, tal como se explica en la cita de González Von Marées, el "saber ser...".

\footnotetext{
63 Robertson, Erwin. 1986. El Nacismo Chileno, p. 43.

64 Ibíd.

65 Ibíd., p. 35.
} 


\section{Concepción nacista de la sociedad (II): Posición sobre las organizaciones de trabajadores y los sindicatos}

Otro aspecto de la sociedad nacista era la visión del rol que le asignaban a las organizaciones de trabajadores, los derechos de los mismos, y la noción del trabajo que iba más allá de una relación social destinada a la producción-salario.

Al igual que gran parte de la doctrina nacista, este punto fue conflictivo, sin perjuicio que su construcción buscó elaborar una concepción genérica y abierta, tal como se explicó en el acápite anterior, posibilitando la captación de nuevos militantes. Uno de los puntos conflictivos fue que los nacistas rechazaban la visión materialista de la sociedad, por lo que el trabajo difícilmente era visto bajo una perspectiva que ponía de relieve la fuerza de trabajo del trabajador, su relación con el salario percibido, y con ello la proporción directa o inversa que se daba a lugar en diversos sistemas económicos, tanto capitalistas como socialistas.

Lo anterior tuvo consecuencias, ya que el liberalismo y su concepción materialista y capitalista eran hegemónicas, y en su contraparte, el marxismo, había elaborado una crítica a esa concepción. Esto implicaba que tanto sectores empresariales como trabajadores discutían asuntos salariales, y de representación al interior de los trabajos, mientras que el discurso nacista, vadeaba entre el respeto al trabajador y al empresario, y sobretodo el "saber ser". Esto no generaba ninguna posibilidad de inserción en frentes sindicales, ni patronales. El nacismo quedaba marginado de la discusión por reajustes salariales, siendo algo crítico en la década de los treinta, donde las repercusiones del crack del 29' aún tenían eco.

Los nacistas percibían que no se debía centrar -ni agotar- toda la crisis económica y política en la búsqueda de mejoras salariales, sino más bien en la dignificación del trabajo y su puesta en valor, dotándola de sentido. Esta visión espiritual, casi escatológica, entró en crisis a medida que fue pasando la década de los treinta, al punto que llegaron a aceptar la lucha de clases, la revolución social, la lucha anti-imperialista y el dominio de una clase por sobre otra $^{66}$, aún más, hasta condenaron el fascismo. Sin embargo, la aceptación de la lucha de clases, y otras banderas muy propias de las izquierdas de aquella época, se dieron a lugar una vez que pasaron a denominarse Vanguardia Popular Socialista ${ }^{67}$.

Otro punto de conflicto fueron las mismas bases militantes, puesto que si bien es cierto, tal como se planteó al comienzo de este estudio, la militancia nacista estaba conformada en gran parte por los sectores mesocráticos y profesionales, existiendo también un sector latifundista, particularmente los militantes del sur -en Concepción, Temuco y Osorno-no veían con

\footnotetext{
66 Vanguardia Popular Socialista. 1939. Declaración de Principios de la Vanguardia Popular Socialista, Santiago de Chile, Editorial Vanguardia, p. 3.

67 lbíd., p. 5.
} 
buenos ojos el avance y robustecimiento del movimiento obrero ${ }^{68}$. A pesar de que las bases militantes descritas se sintieran mejor interpretadas con una concepción $-\mathrm{y}$ programa político- que no cuestionase las relaciones capital-trabajo, la concepción espiritual y de responsabilidad social mermó la inserción del nacismo en los sectores populares.

La consigna de "hombres, antes que programas" ${ }^{69}$ daba cuenta de la real vocación de flexibilidad teórica, algo muy propio de las organizaciones nacionalistas y populistas. El hecho de buscar la dignificación de las profesiones y oficios, y el rol de los trabajadores en el desarrollo nacional nos permite reafirmar el hecho de que su visión constituía una aspiración genérica, no posiciones concretas referidas al sindicalismo, ni al rol de los sindicatos. No obstante, es preciso mencionar que gran parte de su repulsión hacia los esquemas y programas rígidos, no se debía solamente a una concepción consciente de flexibilidad, sino una crítica a las concepciones, que ellos concebían como "dogmáticas" de la sociedad, puntualmente, el liberalismo y el comunismo.

A pesar de los planteamientos generales, algunas opiniones concretas permiten desentramar la posición que tenían respecto a los trabajadores, sus derechos y las organizaciones sindicales.

Los aspectos de la doctrina nacista que refieren a la problemática sindical son muy tangenciales, y se caracterizan por posicionarse desde la crítica y la lógica del deber, muestra de ello son: 1. La crítica al asambleísmo, en el cual consideran que impera la demagogia, la voz más pasional, y no el análisis mesurado y reflexivo, que se atiene a las consecuencias de las decisiones políticas que ellos someten a votación. Esta crítica al asambleísmo, no la circunscriben solo a las organizaciones sindicales, sino también a las organizaciones políticas en general ${ }^{70} ; 2$. La instrumentalización del término "justicia social", que según los nacistas, ha sido principal herramienta del "divisionismo" de clases -en referencia al marxismo-, explotando "los dolores y sufrimientos del pueblo con fines demagógicos" ${ }^{71}$. Ellos veían una alianza entre el capitalismo y "el comunismo moscovita": los primeros explotaban, y los segundos, so pretexto de redención, anarquizaban la sociedad; 3. Visión de los "gremios". Sobre ellos, los nacistas veían que no cumplían un rol de protección de los trabajadores, ni tampoco de contribución al desarrollo nacional. En efecto, los nacistas consideraban que respondían a intereses del caudillo de turno, y a lo más, a intereses exclusivos del sector productivo que representaban. No veían que estuvieran dentro de un engranaje social, sino más bien, una absoluta falta de coordinación. Ante ello proponían la integración de los

\footnotetext{
68 Cassigoli, Rossana. 2013. "Sobre la presencia nazi en Chile”, en Acta Sociológica, № 61, México D.F., p. 170.

${ }^{69}$ Movimiento Nacional Socialista de Chile. 1932. Ideario nacista, Santiago de Chile, Imprenta Cóndor, p. 6.

70 Ibíd., pp. 9-10.

71 Todo intento de denuncia, y exposición de las miserias de la clase trabajadora chilena, era vista por el nacismo como demagogia y herramienta de división, alimento de autodenominados "redentores". En Ibíd., pp. 13-14.
} 
gremios al Estado, siendo vigilados por este, y estando en correlato con el desarrollo económico chileno.

La visión nacista de los gremios es lo más cercano a una visión sindical concreta, y es también una de las posiciones que más revela su cercanía a los fascismos europeos. Los nacistas, al igual que sus influencias europeas, veían al trabajador como la base del engranaje social $^{72}$, mediados por los gremios ante el Estado, a través del cual podían canalizar sus demandas.

Sobre los derechos de los trabajadores no tenían posiciones claras, más allá de que se pudiese desprender que así como el trabajador tenía el deber de servir al Estado, este tenía el deber de asegurar una vida digna, acorde a su función social, tanto al obrero como al trabajador intelectual.

En definitiva, los nacistas concebían las organizaciones de trabajadores dentro de la sociedad, no a través de los sindicatos propiamente tal, sino mediante los gremios, o corporaciones $^{73}$. Sobre este punto, hay visiones disímiles, ya que por un lado se defiende el corporativismo, a veces de forma crítica, pero Keller por otro lado defiende el cooperativismo ${ }^{74}$.

Sobre este último punto, Robertson plantea que los nacistas concebían el corporativismo, desde una concepción de encuadres, tanto sindical como corporativo. En el caso del encuadre sindical, sería la base de la estructura integrada por sindicatos de asalariados y cámaras económicas de patrones; a esto le seguirían las corporaciones propiamente tal, por rama

\footnotetext{
72 "Partiendo del principio, para nosotros indiscutible, de que los gremios habrán de constituir la base de la organización del estado del futuro, nuestro movimiento está dirigido a obtener que los organismos gremiales actúen, no como generadores aislados e inmediatos de los poderes del Estado, al estilo de las agrupaciones políticas liberales, sino que como elementos, perfectamente equilibrados, de un conjunto político superior, representativo de los altos intereses nacionales. Los gremios pasarán, en otras palabras, a constituir las células vitales del Estado, dentro del cual todos ellos actuarán en un ritmo único de expansión y de vida.". Ibíd., p. 38.

73 Robertson, Erwin. 1986. El Nacismo Chileno, p. 35.

74 Años después, Carlos Keller hizo una defensa del cooperativismo contra sus detractores, en un libro que constituye una de sus principales propuestas económicas, después de haber concluido la experiencia nacista. En Revolución en la Agricultura Keller desmenuza el carácter de la economía chilena, y los aspectos sociales y políticos que inciden en ella. Sobre el cooperativismo en particular refiere: "Entre muchos agricultores, el cooperativismo es considerado con desdén, como algo de gente menuda, como una forma de organización popular que en Chile generalmente fracasa, o que tiene que luchar desesperadamente contra administradores fraudulentos. En realidad, tratando de las cooperativas en sí, no hay ningún motivo para mirarlas con ese menosprecio. Han sido ideadas como una forma de organización económica que se sale del marco de todas las restantes: les falta el "alma capitalista". En efecto, todas las demás sociedades -comerciales, de responsabilidad limitada (...)- tienen la particularidad de realizar una finalidad en sí: se aportan capitales con el objetivo de organizar una empresa de producción o comercio para ganar dinero." En. Keller, Carlos. 1956. Revolución en la Agricultura, Zig-Zag, Santiago de Chile, pp. 497-498.
} 
productiva. Es decir, las etapas de estructuración organizativa de las organizaciones sería primero el encuadramiento sindical, para pasar al organizativo ${ }^{75}$.

Esta visión particular del corporativismo ${ }^{76}$, quitaría en resumidas cuentas, toda autonomía e independencia de las organizaciones de trabajadores respecto al Estado. Sin embargo, esta propuesta sería de construcción y no de acción inmediata -parte de un programa político, y no de una política sindical concreta-. La concepción de "todo dentro del Estado, y nada fuera de él”, sería muy propia de los fascismos europeos, y en donde más se notaba la influencia que tenía sobre el nacismo chileno.

\section{Ocaso del nacismo como organización y doctrina: balance}

Las elecciones presidenciales y parlamentarias de 1937 tensaron al nacismo. Ellos levantaron un candidato propio, bajo una coalición liderada por ellos: Carlos Ibáñez del Campo y la Alianza Popular Libertadora. Bajo un programa cercano al corporativismo se irguieron como una alternativa a la derecha representada por Gustavo Ross, quien era sindicado como el más fiel representante del capitalismo ultra monetarista; y por otro lado representando a la izquierda, Pedro Aguirre Cerda, respaldado por la coalición Frente Popular.

Si bien es cierto, el desprecio que sintieron hacia el comunismo los situaba en una cómoda posición con Ross, ciertos ejes de crítica al capitalismo los acercaban a la izquierda. Dichas elecciones fueron una de las más reñidas en la historia republicana chilena, pues la decisión no era fácil, y esto se vio reflejado en la votación electoral. Ante esta coyuntura, ¿qué rol iba a jugar el nacismo en dicha elección? Su carácter difícilmente codificable en los ejes izquierdaderecha, y una militancia que apelaba a lo nacional, y no a la clase, hizo que ganara adeptos a ambos lados del espectro. El rol que cumplieron los nacistas, a fin de cuentas, fue dirimir la elección presidencial: o el delfín de Alessandri, reforzando un capitalismo aristocrático, o Aguirre Cerda, y la llegada al gobierno del Partido Comunista y Socialista.

Quien se encargó de definir a los nacistas fue -bajo una cruel ironía- el presidente en funciones: el liberal Arturo Alessandri, con la matanza del seguro obrero ${ }^{77}$, en la cual fusilaron a mansalva a jóvenes nacistas bajo incidentes que se hicieron parecer confusos. No solo volcaron a la "opinión pública" contra Alessandri y Ross, sino que sin meditarlo, los nacistas apoyaron al candidato frente populista, y dieron a la izquierda su primera victoria presidencial $^{78}$.

\footnotetext{
75 Robertson, Erwin. 1986. El Nacismo Chileno, pp. 36-37.

76 Según Robertson, los nacistas habrían sido críticos del corporativismo libre. En Ibíd., p. 37.

77 Droguett dedica una parte de su libro a explicar la matanza del seguro obrero. Dilucida razones, e identifica responsables. En Droguett, Carlos. 1940. Los asesinados del Seguro Obrero, pp. 27-40.

78 Chile, junto Francia y España fueron los únicos países del mundo en que logró vencer la política de los "Frentes Populares" de Giorgi Dimitrov.
} 
La victoria del Frente Popular en Chile, no implicó únicamente un cambio sustantivo en la historia del movimiento obrero y de la izquierda chilena abriendo nuevas posibilidades de construcción política, y la vía electoral como medio válido de conquista social, sino también implicó un cambio radical en los nacistas. Su laxitud doctrinaria -¿o concepción genérica?- y política les aisló en un esquema político cada vez más polarizado, y en donde los ecos de la guerra europea contribuían a aquello. La victoria frentepopulista fue determinante en el cambio de nombre a Vanguardia Popular Socialista ${ }^{79}$. El ibañismo inicial se tornó más difuso, y las contradicciones internas terminaron por quebrar el movimiento. No bastó el nacionalismo para generar una cohesión interna, que les había dado resultados durante la década de los treinta. Definitivamente los nacistas no podían situarse a la izquierda del espectro político. Tal vez una explicación posible fue el fuerte componente de clase, y la inserción del fascismo, que a comienzos de los cuarenta, estaba en decadencia.

Keller entró en abierto conflicto con González Von Mareés, cuya disputa tuvo como resultado su salida del movimiento y la conformación de un nuevo referente nacionalista. Por más que la bandera de lucha de Keller fuese el nacionalismo económico ${ }^{80}$, que le permitiría tener un diálogo más estrecho con socialistas y comunistas, nunca su domicilio político fue la izquierda. Von Marées, en tanto, terminó sus días en el Partido Liberal, y muchos de los exnacistas se plegaron décadas después al Partido Agrario Laborista.

El Movimiento Nacional-Socialista de Chile constituyó una excepción dentro del escenario político chileno. Si bien es cierto, el nacionalismo ha estado presente de forma constante en el sistema de partidos chileno, rara vez había tenido expresión política que diera forma a una organización concreta. Este sentido, los nacistas fueron uno de los pocos grupos que se plantearon la conquista del poder, consiguiendo tener mayor presencia que otras organizaciones de similares características.

Su visión heroico-trágica de la sociedad y del desarrollo de la humanidad se hizo carne con la propia historia del movimiento, coronado por la matanza del seguro obrero, pues claro, esto fue su parte de defunción. De ahí en adelante nada pudo ser igual.

\section{Conclusiones}

La experiencia nacista se circunscribió en un período de crisis económica, que repercutió fuertemente en el sistema de partidos chileno. El capitalismo, que estaba siendo cuestionado durante décadas por las izquierdas -marxista y anarquista- estaba en una etapa en la cual se avizoraba su fin. Las derechas -principalmente la liberal- buscaron justificar la vigencia del

\footnotetext{
79 Cabello, Antonio. 2000. "El Nacional-Socialismo chileno. Breve sinopsis", en Pharos. Arte, ciencia y tecnología, Vol. 7, № 2, Santiago de Chile, pp. 82-83.

80 Keller, Carlos. 1931. La eterna crisis chilena, Santiago de Chile, Editorial Nascimento, p. 56.
} 
sistema. A ello se debe agregar el reciente regreso al camino democrático, que se había iniciado recién en 1932, el mismo año de fundación del movimiento nacional socialista, en donde el temor a un nuevo golpe de Estado, y una dictadura estaba muy presente.

Si bien es cierto la composición política y doctrinaria del nacismo chileno fue variopinta, se ha expuesto en este trabajo que hay tres principales elementos: los sectores ibañistas que dotaron de gran parte a la militancia nacista; el fascismo, que dotó de una propuesta ideológica a la problemática económica y estructural del Estado; y el nacionalismo, que sirvió de base doctrinaria y de ethos. Estos tres elementos conjugados, y relacionados entre sí, fueron la base sobre la que se construyó el nacismo, y con ello el sujeto de cambio y las organizaciones de trabajadores.

Sobre estos dos puntos, la concepción sobre el sujeto de cambio habría estado condicionada por criterios de nacionalidad, sin perjuicio de reconocer la existencia de clases sociales distintas, las que lejos de estar susceptibles a un enfrentamiento por la hegemonía lucha de clases- habrían de colaborar bajo responsabilidades y derechos bien definidos. En este punto, el nacismo naturalizaría la estructuración de la sociedad, pero dotándola de sentido y en directo relato con la propuesta de construcción de sociedad. He aquí una diferencia con el liberalismo y el resto de las derechas, en las cuales las clases acomodadas, no asumían un rol o responsabilidad social.

El nacismo se explicaría como una necesidad de sectores de la sociedad por generar una cohesión social -interclasista inclusive- apelando a un sentimiento o concepto que trascendiera la reafirmación y confrontación de clases, producto de la dura desigualdad que se vivía en Chile post-crack del 29'.

Otro punto que es necesario comentar sobre el sujeto de cambio, es la incidencia del Estado en la construcción de este mismo sujeto, es decir, la nacionalidad habría sido parte de la construcción del mismo Estado. Los grandes personajes -Portales concretamente- habrían tenido directa relación a lo anterior. El nacismo no disoció el nacionalismo con un Estadocentrismo. Es aquí donde se evidencia la mezcla entre nacionalismo y conservadurismo social.

Sobre el sujeto de cambio, y con ello quienes serían potencialmente militantes, lo explica la concepción nacionalista que provenía del ibañismo, más allá del diálogo fluido que pudiese establecerse con el fascismo. En este punto, los nacistas mostraron su estrecho vínculo con la tradición nacionalista y conservadora chilena, en donde gobiernos como el ibañista y el portaliano, realzaban la autoafirmación de nación, trascendiendo clases sociales. En otras palabras, los nacistas recogían y se hacían herederos de esa trayectoria política.

Tal como se ha expuesto en el artículo, en sí la propuesta corporativista no era en absoluto original, ni patrimonio exclusivo de los nacistas, peor aún, les valió ser homologados con el nazismo alemán, más allá de las coincidencias. Sin embargo, el nacismo buscó imprimir un 
sello propio a cada elemento extranjero que adoptaron, ejemplo de ello es el mismo concepto de "encuadramiento", y distancia hacia el corporativismo libre.

Sobre las organizaciones de trabajadores, es manifiesta la influencia fascista, por la propia concepción corporativista. Sin embargo, no hay una propuesta de acción inmediata sobre las organizaciones ya existentes -sindicatos, mutuales, etc.-. Aun así, no deja de ser interesante la propuesta de encuadramiento sindical -tal vez lo más cercano a una política sindical-, la cual no incluye solo a los asalariados, sino también a los patrones. Sin excepción, todos debían organizarse, y tener representación ante el Estado, y dentro del Estado.

Concluyendo, el nacismo podría ser considerado como una expresión heterodoxa, aún más, una síntesis entre tres concepciones doctrinarias, que lograron dialogar bien, como el nacionalismo, conservadurismo social, y el fascismo; tal como se pudo apreciar en la concepción sobre el sujeto de cambio y en las organizaciones de trabajadores. Lo amplio del nacionalismo, lo hizo vincularse con izquierdas y derechas, en una época donde el debate no se traducía exclusivamente entre capitalismo o comunismo, sino entre internacionalismo y nacionalismo. En este punto, los nacistas concebirían el nacionalismo desde una posición conservadora y no de izquierdas como el Partido Socialista.

No obstante, la doctrina nacista y su programa no lograron permear la sociedad chilena, ni siquiera con la matanza del seguro obrero, en donde se dio lugar la última gran ironía del movimiento: jóvenes que buscaron ante todo evitar el avance del marxismo y la izquierda, fueron muertos por un presidente de derecha, al grito de "inuestra sangre salvará Chile!", logrando el triunfo del candidato de izquierda, abriendo un nuevo capítulo en la historia del movimiento obrero y de tercio politico en Chile.

\section{Bibliografía}

Anónimo. 1938. La verdad sobre los sucesos del 5 de septiembre de 1938, Santiago de Chile, Editorial Libertad.

Aránguiz, M. 1933. El 4 de junio, Santiago de Chile, Empresa Zig-Zag.

Boizard, R. 1948. Voces de la política. El púlpito y la calle, Santiago de Chile, Editorial del Pacífico.

Bravo, A. 1933. 4 de junio: festín de los audaces, Santiago de Chile, Empresa Letras.

Cabello, A. 2000. "El Nacional-Socialismo chileno. Breve sinopsis", en Pharos. Arte, ciencia y tecnología, Vol. 7, № 2, Santiago de Chile, pp. 79-84.

Casals, M. 2016. La creación de la amenaza roja. Del surgimiento del anticomunismo en Chile a la "campaña del terror" de 1964, Santiago de Chile, LOM Ediciones.

Cassigoli, R. 2013. "Sobre la presencia nazi en Chile”, en Acta Sociológica, № 61, México D.F., pp. 157177.

Corvalán, L. 2015. “Identidad, ideología y política en el Movimiento Nacional Socialista de Chile, 19321938", en Izquierdas, № 25, Santiago de Chile, pp. 76-119.

Dávila, C. 1950. Nosotros, los de las Américas, Santiago de Chile, Editorial del Pacífico.

Díaz, J. 2016. El movimiento nacional socialista o el nazismo con " $c$ ", Concepción, Editorial Escaparate. 
Díaz, J. 2013. El nacionalismo en Chile: entre el fascismo y el autoritarismo conservador, Madrid, Universidad Nacional de Educación a Distancia (UNED), Tesis para optar al grado de Doctor en Historia.

Droguett, C. 1953. 60 muertos en la escalera, Santiago de Chile, Editorial Nascimento.

Droguett, C. 1940. Los asesinados del Seguro Obrero, Santiago de Chile, Editorial Ercilla.

Garay, Cristian. 2006. El Partido Conservador chileno, 1857-1966. Tendencias internas y conflictos doctrinarios, Madrid, Universidad Nacional de Educación a Distancia (UNED).

González, G. 1975. Memorias. Tomo I, Santiago de Chile, Editora Gabriela Mistral.

González, J. 1932. La concepción nacista del Estado, Santiago de Chile, Imprenta "La Tracción".

González, J. 1936. Pueblo y Estado, Santiago de Chile, Imprenta y Litográfica Antares.

Grez, S. 2013. Magno Espinoza. Pasión por el comunismo libertario, Santiago de Chile, Editorial USACh.

Ivulic, J. 1997. Importancia del Partido Conservador en la evolución política chilena. Santiago de Chile,

Universidad Bernardo O'Higgins.

Jobet, J. 1955. Ensayo crítico del desarrollo económico-social de Chile, Santiago de Chile, Editorial Universitaria.

Keller, C. 1931. La eterna crisis chilena, Santiago de Chile, Editorial Nascimento.

Keller, C. 1956. Revolución en la Agricultura, Santiago de Chile, Zig-Zag.

Klein, M. 2008. La matanza del Seguro Obrero (5 de septiembre de 1938), Santiago de Chile, Globo.

León, R. 1971. Evolución histórica de los Partidos Políticos Chilenos, Buenos Aires, Editorial Francisco de Aguirre.

Marx, C. 1946. El Capital, Buenos Aires, Editorial Tor.

Moller, M. 2000. El Movimiento Nacional Socialista chileno (1932-1938), Santiago de Chile, Pontificia Universidad Católica de Chile, Tesis para optar al grado de Licenciado en Historia.

Moulián, T. 2006. Fracturas. De Pedro Aguirre Cerda a Salvador Allende (1938-1973), Santiago de Chile, LOM Ediciones.

Movimiento Nacional Socialista de Chile. 1932. Declaraciones fundamentales, plan de acción, organización, programa, Santiago, Imprenta "La Tracción".

Movimiento Nacional Socialista de Chile. 1932. Ideario nacista, Santiago de Chile, Imprenta Cóndor.

Partido Socialista. 1936. Programa, Santiago de Chile, Departamento de Publicaciones PS.

Robertson, E. 1986. El Nacismo Chileno, Parral, Ediciones Nuestramérica.

Rodríguez, P. 1971. Manifiesto Nacionalista. Frente Nacionalista Patria y Libertad, Santiago, s/e.

Salazar, G., Pinto, J. 2002. Historia contemporánea de Chile III. La economía: mercados, empresarios y trabajadores, Santiago de Chile, LOM Ediciones.

Thompson, E. 2012. La formación de la clase obrera en Inglaterra, Madrid, Capitán Swing.

Valdés, M. "La transformación del Movimiento Nacional-Socialista de Chile en Vanguardia Popular Socialista. Su accionar político durante el Gobierno del Frente Popular: 1938-1941", en Revista Pencopolitana de Estudios Históricos y Sociales, Vol. 2, Concepción, pp. 55-84.

Valenzuela, E. 2017. La generación fusilada. Memorias del nacismo chileno (1932-1938), Santiago de Chile, Editorial Universitaria.

Vanguardia Popular Socialista. 1939. Declaración de Principios de la Vanguardia Popular Socialista, Santiago, Editorial Vanguardia.

Venegas, D. 2017. Una relación dialéctica. Socialistas y comunistas en Chile (1933-1948), Chillán, Universidad del Biobío, Tesis para optar al grado de Magíster en Historia de Occidente. 